\title{
Complete heart block in rheumatoid arthritis
}

\author{
M. AHERN, J. V. LEVER, AND J. COSH \\ From the Royal National Hospital for Rheumatic Diseases, Bath
}

SUMMARY We report 8 cases of complete heart block ( $\mathrm{CHB})$ occurring in patients with rheumatoid arthritis and review 20 similar patients previously reported. Complete heart block occurs generally in patients with established erosive nodular rheumatoid disease. It usually appears to be sudden and permanent, but progression from minor conduction delays is not uncommon. The characteristic histopathological finding is a rheumatoid granuloma in or near the AV node or bundle of His. If syncope or Stokes-Adams attacks occur, the treatment of choice is the insertion of a permanent pacemaker. The prognosis is good provided no other cardiac lesions occur, whether pericardial, valvular, or myocardial.

The first account of cardiac involvement in rheumatoid arthritis was given by Charcot in $1881,{ }^{1}$ when he described pericarditis both as a clinical and as a necropsy finding in patients with 'rheumatisme articulaire chronique'. No further observations were made for sixty years when Baggenstoss and Rosenberg in $1941^{2}$ noted valvular lesions in association with rheumatoid arthritis. They attributed these to previous, unrecognised rheumatic fever. However, in 1944 they identified granulomas in association with uncomplicated pericarditis and thought this a specific result of rheumatoid arthritis. ${ }^{3}$ Confirmation from other authors followed, ${ }^{4}$ and the first report of complete heart block due to a rheumatoid granuloma involving the conduction pathways was in $1959 .{ }^{5} \mathrm{By}$ then heart block resulting from the different pathological changes of ankylosing spondylitis had been described. ${ }^{6}$

Twenty cases of complete heart block due to rheumatoid arthritis have now appeared in the world literatures. We report 8 further cases and in each case relate development of the heart block to the evolution of the disease and its extra-articular manifestations. Previously, anecdotal evidence had suggested that 'treatment with artificial pacemakers has only rarely been more than temporarily successful' $^{7}$ ' Accordingly we have sought to determine mechanisms of the heart block and its response to treatment.

\section{Case reports}

PATIENT 1

A woman, born in 1908. She had seropositive, erosive

Accepted for publication 12 July 1982.

Correspondence to Dr M. J. Ahern, Royal National Hospital for Rhe umatic Diseases, Bath BA1 1RL. rheumatoid arthritis which started in 1960 at the age of 52. She was subsequently treated with gold, then D-penicillamine. Prednisolone was introduced in 1970 because of persistent active synovitis, and she remains on $5 \mathrm{mg}$ a day. In 1975 bradycardia was found on physical examination on admission to hospital, and an electrocardiogram (ECG) showed complete heart block. In 1979, when she was aged 71 , a demand permanent transvenous pacemaker was inserted following syncopal episodes occurring 4 to 5 times a day, persisting for 2 to 3 minutes. At present she is well and the pacing is satisfactory; there are no peripheral nodules or other extra-articular features of rheumatoid arthritis.

PATIENT 2

A woman, born in 1912. She suffered onset of rheumatoid arthritis in 1973 at the age of 61 . Six months later she was admitted to hospital because of active rheumatoid arthritis, and transient first-degree heart block was found on a routine ECG. She was treated with gold and prednisolone because of progressive erosive disease. In October 1980 an ECG showed second-degree heart block (Mobitz type II) progressing 5 days later to complete heart block (rate $35 /$ minute) (Fig. 1). As there had been no syncopal attacks and she suffered no disability as a result of the heart block, she was not paced but was kept under close observation. In April 1981, 2 falls occurred due to syncope, and a cardiac pacemaker was subsequently inserted. At present she is well, with normal pacemaker function. She has nodules on the ulnar borders of both forearms.

PATIENT 3

A woman, born in 1919. In 1957 at the age of 38 she developed rheumatoid arthritis which was progressive, seropositive, and erosive, with many nodules, scleromalacia, and sicca symptoms. She was treated 

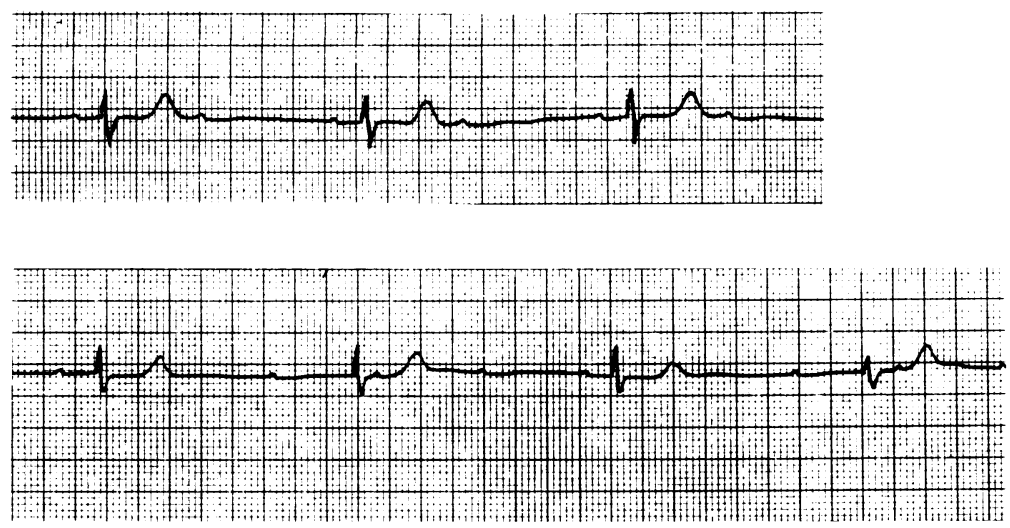

Fig. 1 Patient 2. Above, 20 October 1980; below, 25 October 1980. Rhythm strips (lead II) demonstrating type II second-degree AV block (2:1) progressing to complete $A V$ block. with steroids from 1970 to 1976 , and also gold and subsequently D-penicillamine and cyclophosphamide. In 1977 an ECG showed second-degree heart block, and the following day this had reverted to sinus rhythm. Later the same year she developed Stokes-Adams attacks, and an ECG confirmed complete atrioventricular dissociation. A permanent pacemaker was inserted, and she had no further attacks. In June 1979 signs of aortic incompetence were detected. She died in October 1980 from congestive cardiac failure. Aortic valve replacement was considered but refused because of multiple medical problems.

Post-mortem examination of her heart showed that

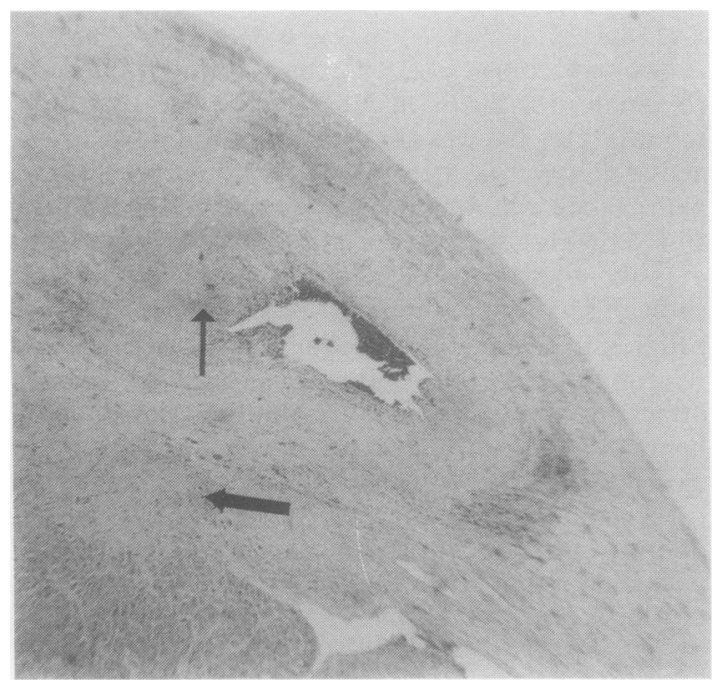

Fig. 2A Rheumatoid nodule (thin arrow) in close approximation to the conduction pathway (thick arrow). The distance between the nodule and the pathway is $0.8 \mathrm{~mm}$ ( $H$ and $E, \times 30$ ). the pacemaker was correctly positioned in the right ventricle, was intact, and functioning normally. There were nodules of typical histological structure in the epicardium, endocardium, and intervent ricular septum. A typical rheumatoid nodule was found in close approximation to the conduction pathway (Figs. 2A, B). The aortic valve cusps were thickened owing to oedema and an infiltrate of lymphocytes and plasma cells, but no nodules were present in the valve cusps or valve ring.

\section{PAT IENT 4}

A woman, born in 1903. She developed seropositive rheumatoid arthritis in 1958 at the age of 55. As she

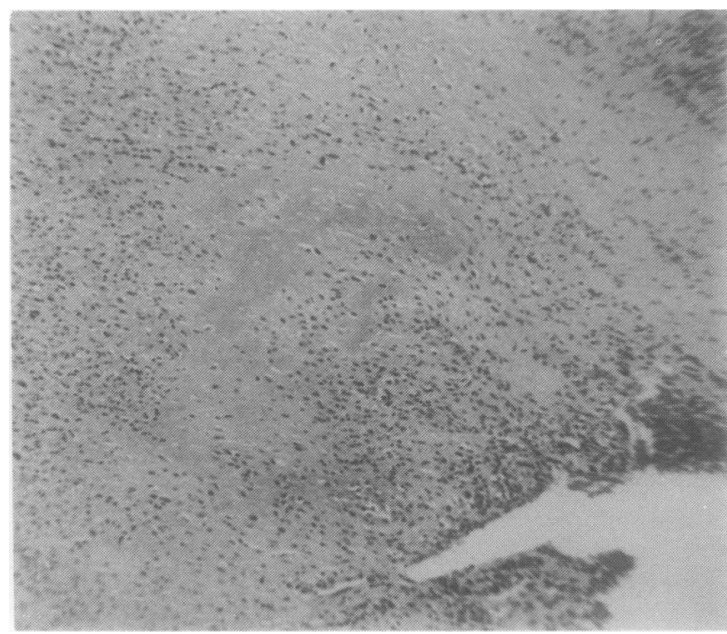

Fig. 2B Magnification of the rheumatoid granuloma consisting of central fibrinoid necrosis and surrounding chronic inflammatory cells. $(H$ and $E, \times 60)$. 
had a progressive erosive arthropathy, she was treated with gold, steroids, and later azathioprine. She had subcutaneous nodules and keratoconjunctivitis sicca. In 1974 she developed cervical cord compression and, later in the same year, septiciaemia due to urinary infection. Also in 1974 she was found to have left anterior hemiblock, with brief periods of complete block combined with left bundle branch block. Throughout 1975 there was varying 2:1 and $1: 1$ atrioventricular conduction with left bundle branch block, and she developed complete heart block (Fig. 3) shortly before her death in June 1976. A pacemaker was not inserted as she was severely disabled and chairbound, and had no syncopal episodes. Post-mortem examination was not performed.

PATIENT 5

A man, born in 1900. In April 1960 he developed rapidly progressive seropositive rheumatoid arthritis, and soon after the onset was treated with corticosteroids. In June 1961 nodules developed on both forearms. There was evidence of vasculitis with mononeuritis multiplex affecting the ulnar nerve of both forearms. $X$-rays of his hands and feet showed progressive erosive changes of the metatarsophalangeal and metacarpophalangeal joints. In June 1962 he developed a Stokes-Adams attack. An ECG showed complete heart block with a rate of 30 per minute. He was treated with isoprenaline, as a pacemaker service was not then available. He died suddenly 3 months later at home. A post-mortem examination was not performed.
PATIENT 6

A woman, born in 1905 . She developed rheumatoid arthritis in 1963 at the age of 58; it was erosive, nodular, and progressive. Steroids were started in 1967 , as there had been only a temporary remission with gold therapy. In 1970 Stokes-Adams attacks occurred, with complete heart block, and a fixed-rate Devices pacemaker was inserted. However, 2 months later competition with the pacemaker occurred, with an episode of atrial tachycardia. This arrhythmia was controlled with propranolol, but she developed bilateral ankle oedema, and her intrinsic heart rhythm continued to compete with the pacemaker. As a result the fixed-rate pacemaker was replaced by a demand Devices pacemaker. She died 12 months later from congestive cardiac failure, and the pacemaker was functioning normally prior to her death.

Post-mortem examination of the heart showed an enlarged left ventricle. The tip of the pacemaker was in its correct position in the right vent ricle. The mitral valve cusp was thickened, and there were nodules in the valve ring (Fig. 4). The other valves were normal. The coronary arteries showed minimal atheroma. Histopathology of one of these nodules showed a typical rheumatoid granuloma with fibrinoid necrosis and chronic inflammatory cell infiltration. The atrioventricular node showed diffuse infiltration with lymphocytes, plasma cells, and histiocytes. In the left bundle branch there was an area of granulation and fibrous tissue, characteristic of a rheumatoid nodule with fibrinoid necrosis and poorly formed palisades of fibroblasts.

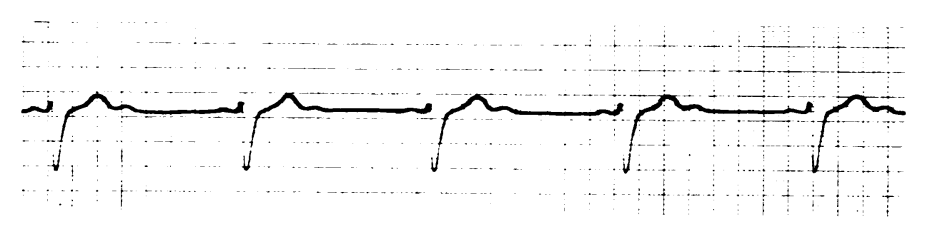

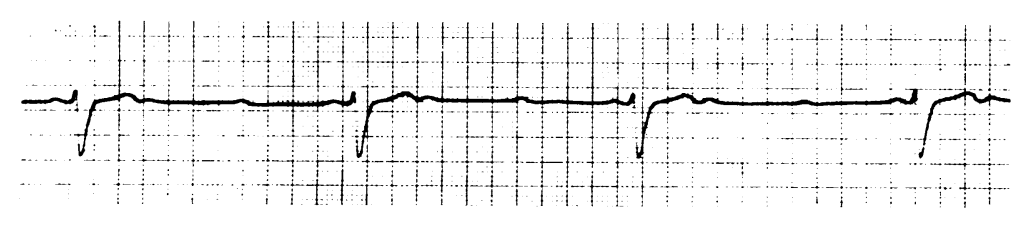

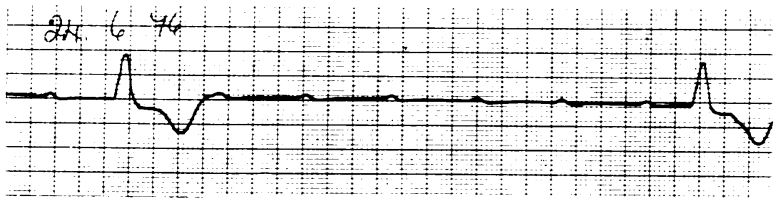

Fig. 3 Rhythm strips showing sinus rhythm with $2: 1$ atrioventricular block (top, 17 February 1976) progressing to 3:1 (middle, 4 May 1976), and finally complete heart block (bottom, 24 June 1976). The sinus rate is 108 beats/min. 


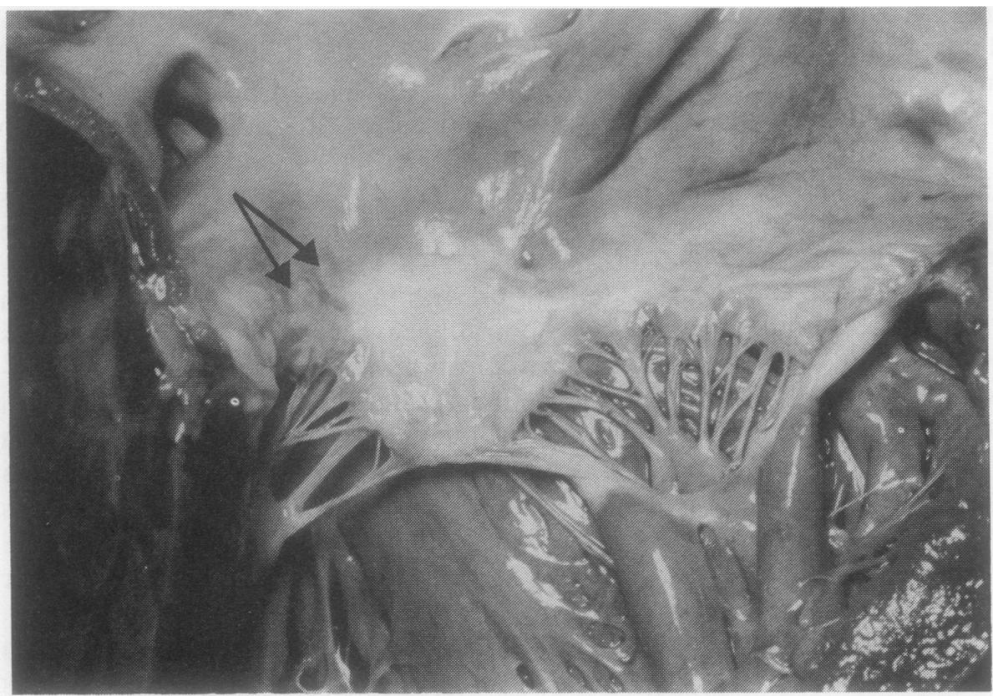

Fig. 4 Patient 6. Thickened mitral valve cusp and nodules (arrowed) in the valve ring.

\section{PATIENT 7}

A woman, born in 1911. She developed seropositive erosive nodular rheumatoid arthritis at the age of 30 in 1941 . This was treated with courses of gold therapy and later corticosteroids. In 1974 she had 3 syncopal episodes persisting for 1 to 2 minutes, and an ECG showed complete heart block. An endocardial demand pacemaker was inserted, which was replaced by a fixed-rate pacemaker after 12 months because of battery failure. She was well until 1978, when further syncopal episodes occurred, and the pacemaker unit was replaced with a Vitatron demand pacemaker. At present she is well, and her rheumatoid arthritis is in remission.

\section{PAT IENT 8}

A woman, born in 1910 . She developed seropositive rheumatoid arthritis in 1972 aged 62 . She was treated with D-penicillamine in 1973 but developed thrombocytopenia, leading to the drug being withdrawn. Steroids were started in 1974. On 14 June, 1974 she became dyspnoeic, and an ECG showed complete heart block. On 17 June she was in second-degree heart block and later the same day first-degree. On 19 June she had returned to sinus rhythm (Fig. 5). An
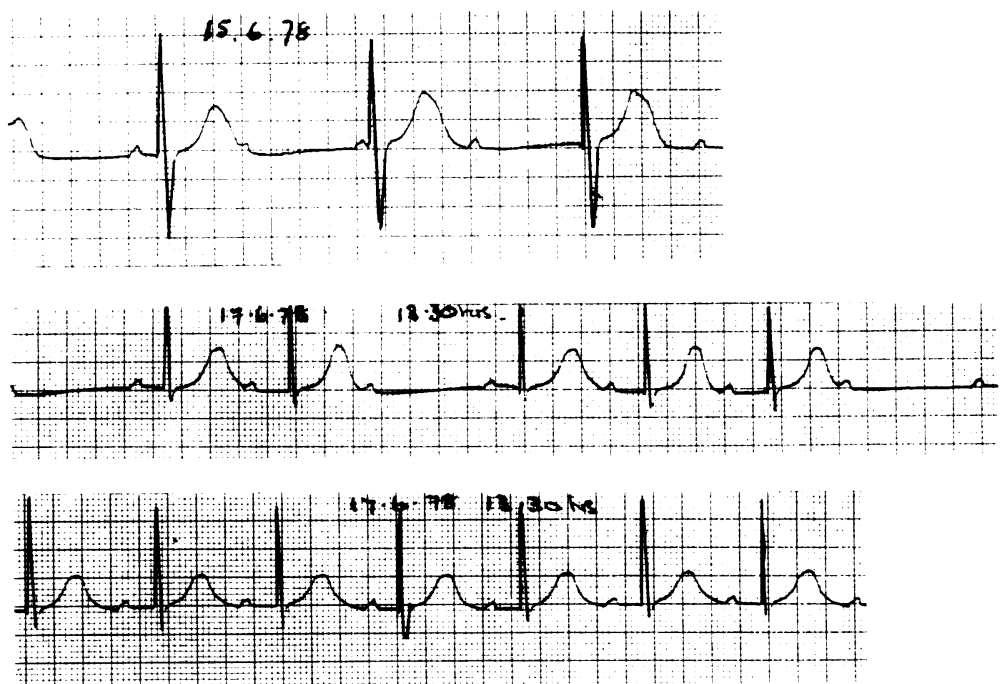

Fig. 5 Patient 8. Rhythm strips, (lead II). Top: 15 June 1978, total heart block.

Middle: 17 June 1978, second-degree block. Bottom: 17 June 1978, first-degree block. 


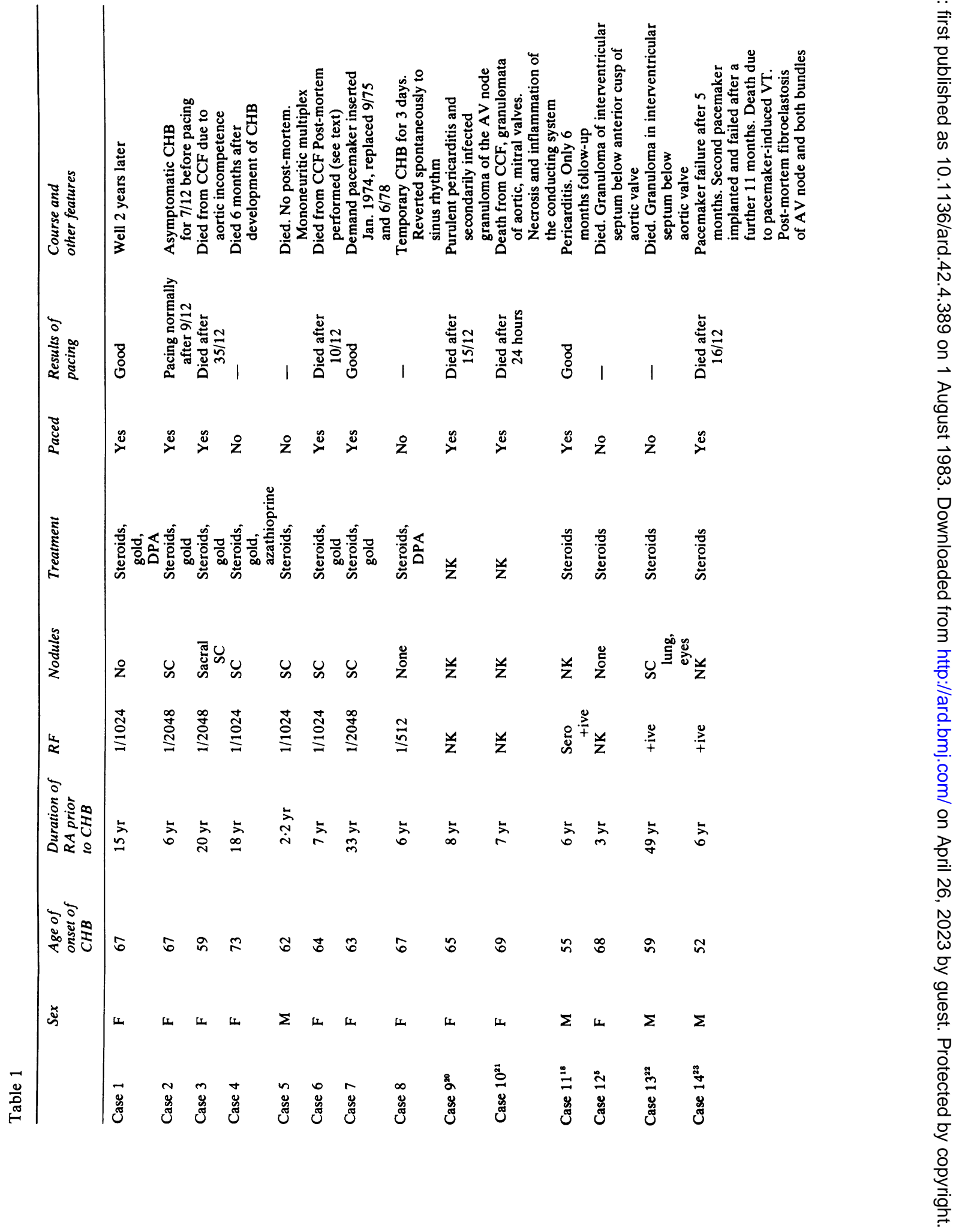




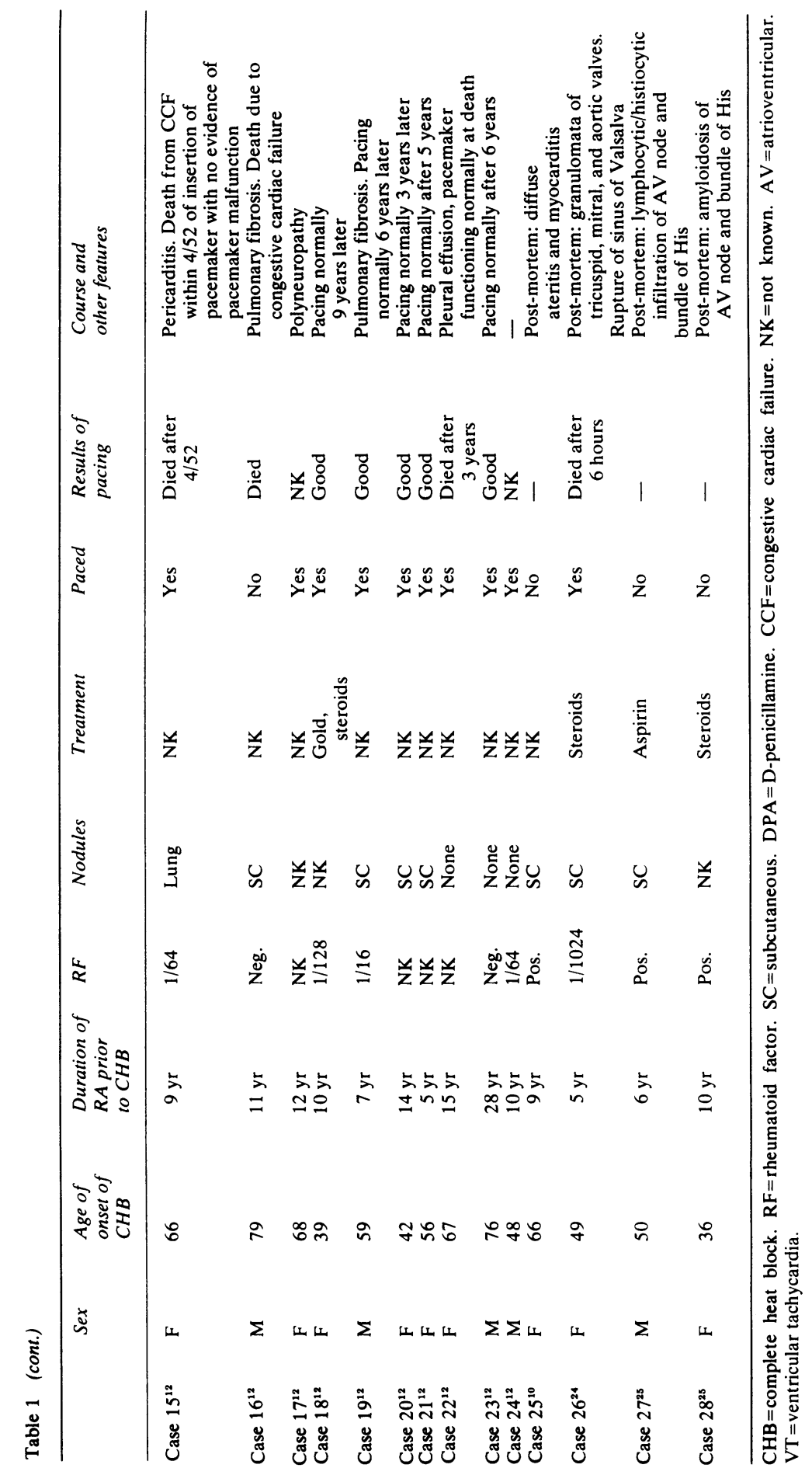


echocardiogram showed no evidence of a pericardial effusion or pericardial thickening. There were no cardiac enzyme changes to suggest recent myocardial infarction. In 1980 when last seen she was well, asymptomatic and in sinus rhythm.

\section{Literature review}

There have been 20 patients (cases 9-28 in Table 1) with complete heart block and rheumatoid arthritis previously reported. Details of these patients are often incomplete. Including our own patients, we make the following generalisations.

\section{SEX AND AGE}

The female-to-male ratio is 19 to 9 , the average age of developing complete heart block is $60 \cdot 2$ years (range 36-79), and the duration of rheumatoid arthritis prior to the development of the block is a mean of $12 \cdot 0$ years (range $2 \cdot 2-49$ years).

\section{PACING AND SURVIVAL}

Nineteen of the 28 patients have had pacemakers inserted. Of these 19 patients 8 have died, 2 within 24 hours of insertion of the pacemaker, one within 4 weeks, 3 within 24 months, and 2 at 3 years. The causes of death in 7 of these patients were congestive cardiac failure in 4 , infection in 1 , intractable ventricular tachycardia in 1 (no. 26), pacemaker-induced arrhythmia in 1 (case no. 14), and the cause of death was unknown in 1 patient (no. 22), but her pacemaker was functioning normally at death. Thus of these 19 paced patients only 3 have had an unsatisfactory response to pacing, and one of these died from congestive cardiac failure due to valvular involvement with rheumatoid granulomata.

Of the 9 patients not treated with pacemakers only 1 has survived and she had temporary complete heart block persisting for 3 days only. Of the 8 deaths in the unpaced group 7 occurred within 6 months of the development of complete heart block. This incidence was significantly higher than in the paced group, where only 3 out of 8 deaths occurred within 6 months of pacing $\left(\chi^{2}=4 \cdot 267, p<0 \cdot 05\right)$. However, in a retrospective study such as this the availability of pacing and selection of patients influence the results. In the earlier years patients sometimes died because no pacemaker service was then available.

\section{EVOLUTION OF BLOCK}

Complete heart block usually appeared to develop suddenly, being discovered after syncope or found unexpectedly on periodic physical and electrocardiographic examination. However, a number of published reports, as well as our own observations, show that lesser degrees of block may precede complete heart block for varying periods, sometimes with intervening periods of normal conduction. Our patient no. 2 was found to have temporary firstdegree heart block 7 years before complete heart block developed and second-degree block for 5 days beforehand. Patient 3 was in second-degree block for 24 hours, reverting spontaneously to sinus rhythm, but developing complete heart block one month later. Patient 4 had varying 2:1 and 1:1 atrioventricular conduction, with left hemiblock or left bundle branch block for 2 years before progressing terminally to complete block. Patient 11 had both firstdegree block and left bundle branch block leading to second-degree block before complete atrioventricular dissociation. Patients 18 and 21 had preceding right bundle branch block and incomplete left bundle branch block respectively.

\section{PATHOLOGY}

The histopathology of the conducting system was only available in 2 of our 8 patients. Where available, the characteristic finding is a granuloma in or near the A $V$ node of the His bundie (cases 3, 9, 12, 13), but also infiltration of the conducting system by lymphocytes, plasma cells, and histiocytes has been described (cases 6,10 , and 27 ). In case 14 , where fibroelastosis of the conduction system was found, the authors speculated that this was the end result of healed granulomas in the region of the bifurcation and the origin of the bundle branches. ${ }^{8}$ However, a similar change has been described in association with idiopathic bundle branch fibrosis. ${ }^{9}$

Thery (case 28) described a female with rheumatoid arthritis and complete heart block due to amyloid infiltration of the AV node and bundle of His. An unusual cause of complete heart block occurred in case 26 , where haemorrhage into a rheumatoid nodule resulted in perforation of the sinus of Valsalva and destruction of the AV node.

Lebowitz decribed 2 patients, ${ }^{10}$ one with complete heart block and the other with atrial flutter, who at post-mortem had evidence of healed arteritis, with perivascular fibrosis and infiltrates of lymphocytes and plasma cells throughout the myocardium. Unfortunately the location and extent of involvement of the conduction system was not reported. Nevertheless, arteritis affecting the conduction system remains a theoretical possibility.

\section{Discussion}

Complete atrioventricular dissociation is a rare complication of rheumatoid arthritis. Our 8 patients occurred among an inpatient population of over 7500 seen over a period of 15 years at the Royal National Hospital for Rheumatic Diseases, Bath. This gives an approximate incidence of 1 in 1000 patients with 
rheumatoid arthritis sufficiently severe to require inpatient treatment.

In the series of 100 patients with newly developed arthritis followed up for 18 years by Rasker and $\operatorname{Cosh}^{11}$ one developed complete heart block, giving an incidence of 1 in about 1600 patient years. One other developed first-degree block and at necropsy was found to have a granuloma ajoining the AV node. Chaussé et al.'s 10 patients ${ }^{12}$ with complete heart block were found over a period of 18 years among 1400 patients attending hospital with rheumatoid arthritis.

Complete heart block in rheumatoid arthritis occurs generally in patients with established erosive nodular rheumatoid disease. All our patients except one had other extra-articular features and/or a high titre of rheumatoid factor. All these patients were categorised in anatomical stage 3 or 4 according to the criteria of Steinbrocker et al. ${ }^{13}$ and all had been treated with corticosteroids. This may reflect the severity of their rheumatoid disease, but also these patients were seen during a period when corticosteroid usage was more common. As corticosteroid therapy has been implicated in the development of necrotising arteritis ${ }^{14}$ in rheumatoid arthritis, it is pertinent to consider whether corticosteroids had contributed to the development of complete heart block in this way. There was evidence of systemic vasculitis in only one patient (no. 5). The presence of vasculitis was not specifically sought in the other 7 patients, so that the presence of systemic vasculitis may well be underrepresented. Localised vasculitis affecting the arterioles supplying the conduction pathways without systemic manifestation is theoretically possible, but to our knowledge not reported. Nevertheless the same features of arteritis with the end result of thick-walled narrow vessles have been reported without steroid administration. Moreover our patients were generally on other drugs, particularly gold therapy and penicillamine, which modify the disease process.

The transition from sinus rhythm to complete heart block usually appears to be sudden and permanent. However, there may be a progression from firstdegree heart block or blocks of the bundles or their fascicles to second-degree heart block and finally complete heart block. It seems probable that such changes are not uncommon but are unobserved. Ambulatory electrocardiographic monitoring would be helpful in this situation, and would allow detection of temporary rhythm disturbances and their response to therapeutic measures. The efficacy of pacemakers can also be monitored with this technique. Spontaneous recovery from complete heart block is possible, and this has occurred in one of our patients. It could have been due to oedema or a vasculitic lesion in or near the conduction system.
Complete heart block may also be asymptomatic. This is quite possible in a patient whose physical activities are severely limited, as may occur in rheumatoid arthritis. Once the danger of syncope or asystole has been removed by implantation of a pacemaker, the prognosis generally is reasonably good and becomes that of the rheumatoid disease, although in our experience this is usually severe, with a destructive erosive arthropathy and extra-articular lesions. Other rheumatoid cardiac lesions may also be present, such as pericarditis or aortic and mitral valve involvement, which obviously modify the patient's prognosis. Moreover patients with chronic congestive cardiac failure before permanent pacing have an adverse prognosis. ${ }^{1516}$

From the 10 cases in which histological studies have been made of the conducting system in rheumatoid arthritis the following mechanisms for the conduction disturbance can be invoked: (1) direct involvement of the conducting system with granulomas; (2) extension of the inflammatory process from the base of the aorta or mitral valves to the conduction pathways; (3) amyloidosis; (4) haemorrhage into a rheumatoid nodule.

As only 2 of our patients had histopathological studies of their conduction system, absolute proof of the above mechanisms occurring in our patients is lacking. Our patients are elderly (mean age of developing complete heart block 62 years) and therefore could develop complete heart block as a result of idiopathic bundle branch fibrosis or arteriosclerosis. The mean age of onset of patients with complete heart block due to ischaemic heart disease or bundle branch fibrosis is 67 years. ${ }^{17}$ However, there was no history of angina or myocardial infarction in our 8 patients and the nature of their rheumatoid disease was similar.

Electrocardiography of the bundle of His has been performed in only one patient with complete heart block and rheumatoid arthritis (patient 11). It revealed a normal $\mathrm{AH}$ interval and a prolonged $\mathrm{HV}$ interval of $300 \mathrm{~ms}$ (normal $41 \pm 4 \mathrm{~ms}$ ) ${ }^{18}$ indicating that the conduction delay was in or below the bundle and not in the atrioventricular node. The advantage of this procedure is that it localises the level of the $\mathrm{AV}$ block. ${ }^{19}$ If the clinical indication for pacing is thought to be uncertain due to the absence of syncope and/or the bradycardia is faster than 40 beats per minute, localisation of the level of the block becomes important. This localisation can predict the course, and therefore the most suitable form of treatment. For example, a block below the bundle of His predisposes to Stokes-Adams attacks, and therefore a pacemaker is indicated in second-degree or complete heart block, even if the patient is asymptomatic.

Chaussé et al. ${ }^{12}$ reported in his group of patients the 
occurrence of high thresholds of excitability during the insertion of the transvenous pacemakers. However, this has not been our experience with normal thresholds obtained, and that may relate to different pathogenic mechanisms of the heart block.

The authors thank Drs D. Wainwright Evans and H. A. Fleming, Papworth Hospital, Cambridge, for allowing us to report details of cases 6 and 7 .

We are grateful to Mrs Carole Andrews for secretarial assistance.

\section{References}

1 Charcot J L. Clinical lectures on senile and chronic diseases. London: Sydenham Society, 1881; 95: 172-5.

2 Baggenstoss A H, Rosenberg E F. Cardiac lesions associated with chronic infectious arthritis. Arch Intern Med 1941; 67: 241-8.

3 Baggenstoss A H, Rosenberg E F. Unusual cardiac lesions associated with chronic multiple rheumatoid arthritis. Arch Pathol 1944; 37: 54-60.

4 Sokoloff L. The heart in rheumatoid arthritis. Am Heart J 1953; 45: 635-43.

5 Handforth CP, Woodbury J F. Cardiovascular manifestations of rheumatoid arthritis. Can Med Ass J 1959; 80: 86-90.

6 Shilder D P, Harvey W P, Hufnagel C A. Rheumatoid spondylitis and aortic insufficiency. $N$ Engl $J$ Med 1956; 255: 11-7.

7 Iveson J M I, Pomerance A. Cardiac involvement in rheumatoid disease. Clin Rheum Dis 1977; 3: 492.

8 Lev M, Bharati S, Hoffman F G, et al. The conduction system in rheumatoid arthritis with complete atrio-ventricular block. Am Heart J 1975; 90: 78-83.

9 Davies $\mathrm{M} \mathrm{J}$. A histological study of the conduction system in complete heart block. J Pathol Bacteriol 1967; 94: 351-8.

10 Lebowitz W B. The heart in rhe umatoid arthritis-a clinical and pathological study of 62 cases. Arch Intern Med 1963; 58: 102-23.
11 Rasker J J, Cosh J A. Cause and age at death in a prospective study of 100 patients with rheumatoid arthritis. Ann Rheum Dis 1981; 40: 115-20.

12 Chaussé J D, Blanchot P, Warin J, et al. Atrio-ventricular block in rhe umatoid arthritis. Rev Rheum Mal Osteoartic 1976; 43: 177-83.

13 Steinbrocker O, Traeger C H, Batterman R C. Therapeutic criteria in rhe umatoid arthritis. JAMA 1949; 140: 659-62.

14 Kemper J W, Bagenstoss A H, Slocumb C H. The relationship of therapy with cortisone to the incidence of vascular lesions in rheumatoid arthritis. Ann Intern Med 1957; 46: 831-51.

15 Simon A B, Zloto A E. Atrioventricular block: natural history after permanent pacing. Am J Cardiol 1978; 41: 500-7.

16 Bernstein V, Peretz D I. Permanent pacemakers: 8-year follow up study. Ann Intern Med 1971; 74: 361-9.

17 Rowe J C, White P D. Complete heart clock: a follow up study. Ann Intern Med 1958; 49: 260-70.

18 Gelson A, Sanderson J M, Carson P. Rheumatoid pericardial effusion with heart block treated by pericardiectomy and implantation of permanent pacemaker. Br Heart J 1977; 34 113-5.

19 Puech P. Atrioventricular block: the value of intracardiac recordings. In: Krikler D M, Goodwin J F, eds. Cardiac arrhythmias. New York: Saunders, 1975: 81-115.

20 Gallagher P J, Gresham G A. Heart block with infected cardiac rheumatoid granulomas. Br Heart J 1973; 35: 110-2.

21 Harris M. Rheumatoid heart disease with complete heart block. J Clin Pathol 1970; 23: 623-6.

22 Gowans J D C. Complete heart block with Stokes-Adams syndrome due to rheumatoid heart disease. $N$ Eng J Med 1960; 262 $1012-4$.

23 Hoffman F G, Leight L. Complete atrio-ventricular block associated with rheumatoid disease. Am J Cardiol 1965; 16: 585-92.

24 Howell A, Say J, Hedworth-Whitty R. Rupture of the sinus of Valsalva due to severe rheumatoid heart disease. Br Heart $\mathrm{J}$ 1972; 34: 537-40.

25 Thery C, Lekeiffre J, Grosselin B, et al. Le bloc auriculoventriculaire de la polyarthrite rheumatoide. Etude histologique du système de His-Tawara. Arch Mal Coeur 1974; 10: 1181-91. 